\title{
Management of obesity in cats
}

This article was published in the following Dove Press journal:

Veterinary Medicine: Research and Reports

I September 2014

Number of times this article has been viewed

\section{Kirsten M Hoelmkjaer Charlotte R Bjornvad}

Department of Veterinary Clinical and Animal Sciences, Faculty of Health and Medical Sciences, University of Copenhagen, Frederiksberg, Denmark
Correspondence: Charlotte R Bjornvad Department of Veterinary Clinical and Animal Sciences, Faculty of Health and Medical Sciences, University of Copenhagen, 16 Dyrlaegevej, Frederiksberg 1870, Denmark

$\mathrm{Tel}+4540224682$

Email crb@sund.ku.dk
Abstract: Obesity is a common nutritional disorder in cats, especially when they are neutered and middle-aged. Obesity predisposes cats to several metabolic and clinical disorders, including insulin resistance, diabetes mellitus, lameness, and skin disease. Prevention and treatment of obesity is therefore of great importance in veterinary practice. Correct assessment of body composition is important for recognizing early states of obesity and for monitoring success of weight-loss programs. Various methods for assessing body composition have been proposed, of which a 9-point body-condition score has been validated in cats, and is possibly the most simple to use in the clinic; however, for extremely obese individuals, it is less useful. When calculating the appropriate daily caloric intake for a weight-loss plan, the aim is to maintain a safe weight-loss rate, increasing the chance of preserving lean body mass and decreasing the risk of developing hepatic lipidosis, while also producing a sufficient weight-loss rate to keep owners motivated. A weight-loss rate of $0.5 \%-2 \%$ per week is recommended, which for a cat that needs to lose $3 \mathrm{~kg}$ body weight results in an anticipated time for reaching the target weight of 24-60 weeks. There are several purpose-made weight-loss diets available. The optimal composition of a weight-loss diet for cats is unknown, but most of the available products have lower caloric density, an increased nutrient:energy ratio, and higher protein and fiber content. Regular follow-up visits allow the caloric intake to be adjusted based on progress, and possibly increase the chance of success. This review discusses the risk factors for and consequences of obesity, and gives directions for formulating a weight-loss plan, including daily caloric intake, choice of diet, and common problems based on the current literature. This review further provides a nutritional comparison of the current composition of selected commercial veterinary-specific weight-loss diets.

Keywords: body condition, glucose intolerance, veterinary weight-loss diets, weight-loss management

\section{Introduction}

Obesity is a common problem in pet cats. In humans, the prevalence of obesity has increased dramatically in recent years, and it is believed that prevalence in cats may also be increasing. Obesity in cats is associated with an increased risk of medical complications, such as diabetes, lameness, and skin disease. Further, a number of metabolic changes occur, which may not be obvious on routine clinical or laboratory evaluation. It is therefore highly important for clinicians and owners regularly to monitor weight changes and initiate proper action to prevent or treat unwanted weight gain. When establishing a weight-loss protocol, there are many factors to consider including determining target body weight (TBW), daily caloric allowance, and diet selection. 


\section{Definition}

Obesity is often defined as a body-fat percentage (BF\%) above $30 \%$, and lean cats are expected to have a $\mathrm{BF} \%$ between $10 \%$ and $30 \% .{ }^{1}$ Few techniques can accurately evaluate $\mathrm{BF} \%$, and this definition is rarely of use in practice. In humans, normalweight obesity is a condition characterized by normal BW and body mass index, despite a high $\mathrm{BF} \%$ and an increased risk of obesity-related diseases. ${ }^{2,3}$ A similar condition may exist in the feline population, particularly in cats confined indoors with a low activity level. A study from our group showed that strictly indoor cats with an ideal body-condition score (BCS) had a $\mathrm{BF} \%$ of $23.6 \%-38.4 \% .{ }^{4} \mathrm{~A}$ recent study supports that indoor neutered cats have significantly higher $\mathrm{BF} \%$ than outdoor intact cats, despite all having similar BCS. ${ }^{5}$ The exact level of obesity to cause pathology in the cat is unknown. ${ }^{6}$

\section{Prevalence of obesity}

It is generally agreed that the prevalence of overweight and obesity is increasing in the domestic feline population. Most prevalence studies are cross-sectional analyses of cats visiting veterinary practices, and thus may not be representative of the entire cat population. Also, various methods have been used for classifying cats as overweight or obese, making direct comparisons between studies difficult. Variations in the demographics of the study populations (eg, neuter status, living conditions, and age), may be confounding factors, since these can be risk factors for obesity. ${ }^{7-10}$ An overview of prevalence studies is presented in Table 1. Increasing prevalence may be questionable based on these studies; however, prevalence was consistently high.

\section{Risk factors \\ Breed and genetics}

There is evidence of some genetic influence on the development of feline obesity. Within a research colony of domestic mixed breeds, an autosomal-recessive major gene affected whether cats displayed a lean or obese phenotype at 8 months of age. ${ }^{11}$

Some studies found that obese cats were more likely to be domestic short- or longhair cats than purebred, while others could not document a breed predisposition., ${ }^{9,10}$ Purebred cats are often underrepresented in these investigations, and any breed predisposition may go undetected due to lack of statistical strength. A recent study found a high prevalence of overweight $(\mathrm{BCS}>5 / 9)$ in purebred cats at a cat show. Certain breeds (eg, British shorthair, Maine coon and Norwegian forest cat) had significantly higher BCS than other breeds (eg, Cornish rex, Abyssinian and sphynx). ${ }^{13}$ Breed genetics may not be the only explanatory factors, as the wording used in the breed standards (eg, sturdy and powerful versus lithe and graceful) was hypothesized to influence the risk of obesity in certain breeds.

\section{Age and activity level}

The prevalence of obesity increases at the age of 2-3 years, peaks in middle-aged cats (5-11 years), and tends to decline in older cats. ${ }^{7-10,12}$ Indoor confinement (a surrogate measure of activity level) was a risk factor for obesity in some studies, but not in others. ${ }^{6-8,12}$ Activity level is difficult to quantify, which may explain the inconsistent results.

\section{Sex and neuter status}

Male sex was a risk factor for obesity in several studies, regardless of neuter status..$^{8-10,12}$ Additionally, neutered cats are more than three times as likely to be overweight than intact cats. $^{6-9,14}$ The exact underlying mechanisms for development of obesity after neutering are controversial. An increased appetite becomes evident shortly after neutering, possibly through a loss of ability to self-regulate food intake. ${ }^{15-17}$ Also, a substantial $(30 \%-40 \%)$ reduction in daily caloric intake is required in

Table I Overview of studies on prevalence of overweight and obesity in client-owned cats

\begin{tabular}{|c|c|c|c|c|c|}
\hline Country & $\begin{array}{l}\text { Year of data } \\
\text { collection }\end{array}$ & $\begin{array}{l}\text { Prevalence of } \\
\text { overweight, \% }\end{array}$ & $\begin{array}{l}\text { Prevalence } \\
\text { of obesity, \% }\end{array}$ & Criteria & Reference \\
\hline Denmark & NS & 27.8 & 12.6 & NS & Sloth \\
\hline New Zealand & 1993 & $25.8^{*}$ & & BCS I-5 & Allan et $a^{89}$ \\
\hline USA & 1995 & 28.7 & 6.4 & BCS I-5 & Lund et $\mathrm{al}^{9}$ \\
\hline USA & NS & 20.0 & 5.0 & BCS I-6 & Scarlett et $\left.\mathrm{a}\right|^{8}$ \\
\hline UK & NS & 48.0 & 4.0 & BCS I-I7 & Russell et $\mathrm{al}^{6}$ \\
\hline France & 2006 & 19.0 & 7.8 & BCS I-5 & Colliard et al ${ }^{12}$ \\
\hline New Zealand & 2007 & $27.4^{*}$ & & BCS I-9 & Cave et $\mathrm{al}^{90}$ \\
\hline UK & 2008 & 28.8 & 10.2 & BCS I-5 & Courcier et al ${ }^{14}$ \\
\hline UK & $2008-2010$ & $11.5^{*}$ & & BCS I-5 & Courcier et $\mathrm{al}^{10}$ \\
\hline
\end{tabular}

Notes: Some studies state a separate prevalence for overweight and obesity, whereas others give a combined prevalence. *These studies did not report a separate prevalence for overweight and obesity, but instead reported a single, combined prevalence of obesity and overweight in the studied population. Abbreviations: NS, not specified; BCS, body-condition score. 
order to prevent weight gain following neutering; this relates to a combination of reduced basic metabolism, though studies are still inconsistent, and a decreased level of physical activity following surgery. ${ }^{15,17-21}$ Age at time of neutering may affect the risk of developing obesity. One study found no difference in weight gain in cats neutered before or after the age of 4 years. ${ }^{20}$ Early neutering (19 weeks versus 31 weeks of age) was shown to affect the plasma metabolome; however, these changes did not persist beyond one year of age. ${ }^{22}$

\section{Consequences of obesity}

Contrary to earlier beliefs, adipose tissue is a highly active tissue, secreting a vast amount of proteins involved in a broad spectrum of local and systemic processes in the body. ${ }^{23}$ In humans and rodents, obesity results in chronic low-grade inflammation, which is believed to contribute to systemic metabolic dysfunction, including dyslipidemia and insulin resistance. ${ }^{24}$ In cats, obesity has mainly been associated with insulin resistance, diabetes mellitus, nonallergic skin disease, and lameness.

\section{Insulin resistance and diabetes mellitus}

Several studies have shown an association between obesity and diabetes in cats, and it has been estimated that if obese and overweight cats lost weight to normal, $13 \%-18 \%$ of diabetes cases could be eliminated. ${ }^{25-27}$ Feline diabetes shows many similarities with human type 2 diabetes, characterized by peripheral insulin resistance combined with a relative decrease in insulin production. ${ }^{28,29}$ The underlying mechanisms for obesity-induced insulin resistance in cats are complex. Weight gain reduces the expression of the glucosetransport molecule GLUT4 in both muscle and fat. ${ }^{30}$ Weight gain also increases the amount of intra- and extramyocellular lipid, which is associated with increased insulin resistance. ${ }^{31}$ The obesity-induced changes in glucose homeostasis are (at least initially) reversible with weight loss. ${ }^{32}$

\section{Dermatopathy}

Cats with a BCS of 5/5 are more likely to be concurrently diagnosed with unspecified dermatopathy. ${ }^{9}$ Likewise, cats with a BCS of $6 / 6$ are 2.3 times as likely to develop nonallergic skin disease as lean cats. ${ }^{27}$ Clinical symptoms are primarily increased scaling and a dry, dull coat on the caudal part of the body, presumably due to decreased ability to groom.

\section{Lameness}

Obese cats are almost five times as likely to develop lameness as lean cats. ${ }^{27}$ It was proposed that $12 \%-22 \%$ of lameness cases in overweight cats could be eliminated if they lost weight to ideal weight. The exact cause for lameness (eg, osteoarthritis, ligament injury) was not specified in this study. In humans, obesity contributes to the development of lameness, partially through a mechanical overload, and partially through the low-grade inflammation associated with obesity. ${ }^{33}$

\section{Adipokines and inflammation}

Adipokines are proteins secreted by adipose tissue, and they elicit a wide range of local and systemic effects. ${ }^{23,24,34}$ Secretion patterns of adipokines change with obesity, which influences several metabolic pathways, including insulin sensitivity. In cats, leptin and adiponectin have been most extensively studied.

Serum leptin concentration increases significantly with weight gain, and decreases with weight loss. ${ }^{35-39}$ Insulin resistance increases with increasing leptin concentrations, but it is currently unknown whether an increased leptin concentration is causally involved in the development of insulin resistance in cats. ${ }^{37,40}$ Contrary to leptin, adiponectin is associated with improved insulin sensitivity in several species. ${ }^{24,34,41}$ In cats, the association between obesity and serum adiponectin concentration is inconsistent. . $35,36,39,42,43$ Our group found no correlation between $\mathrm{BF} \%$ and total adiponectin, but the most active isoform - high-molecular-weight adiponectin - was significantly decreased in obese cats. ${ }^{37}$ The role of adiponectin in feline obesity and insulin resistance is not clear, and this area warrants further investigations. ${ }^{37,39,44}$ So far, studies have failed to consistently find increased inflammation in obese cats, which may partly be due to methodological difficulties when measuring feline biomarkers. ${ }^{19,36,39,45-47}$

\section{Quality of life}

In humans, severe obesity can reduce both mental and physical quality of life. ${ }^{48}$ Similar studies have not been conducted in cats. In a study with client-owned obese dogs, the majority of owners believed that their dog's quality of life improved after weight loss. ${ }^{49}$ Owners described an increase in vitality and a decrease in signs of pain after weight loss. ${ }^{49}$ It is our impression that cats likewise become more active after weight loss, but further research in this area is necessary.

\section{Assessment of obesity}

For weight-loss intervention, a reliable method to evaluate the degree of obesity is necessary. There are many proposed methods, but few are extensively validated and some are impractical for general practice. 


\section{Dual-energy X-ray absorptiometry}

Dual-energy X-ray absorptiometry (DXA) is often used in research settings and as a gold standard when validating other methods. It measures bone mass, fat mass, and lean body mass, is validated in several species, and generally has high repeatability. However, precision is consistently poorest for the measurement of fat mass. ${ }^{50,51}$

\section{Body weight}

BW does not assess the degree of obesity, and the ideal BW depends upon breed and stature. ${ }^{52}$ Still, BW is a useful tool for monitoring a weight-loss program, and regular BW registrations are essential for recognizing the early stages of weight gain.

\section{Body-condition score}

Based on inspection and palpation of predefined fat depots, a BCS can be deduced from a predefined scale. The fat covering of the ribcage, presence or absence of a waist, and size of the abdominal fat pad are particularly suitable for assigning BCS in cats. A 9-point BCS scale has been validated in cats, where 1 is emaciated, 5 is ideal, and 9 is grossly obese.,53 A BCS assigned according to this scale has shown good correlation ( $r=0.91, r=0.87$, and $\left.r^{2}=0.808\right)$ with $\mathrm{BF} \%$ measured by DXA in both colony and client-owned cats., ${ }^{4,53,54}$

Despite similar correlations, the $\mathrm{BF} \%$ relating to each BCS unit may differ between populations. A study from our facility found that indoor-confined, client-owned cats had a higher $\mathrm{BF} \%$ than colony cats with similar BCS (Table 2). ${ }^{4}$ The colony cats were not characterized with respect to neuter status or activity level (some were intact, and all were group-housed in a colony [Laflamme, personal communication]), whereas the

Table 2 Means \pm standard deviation of dual-energy X-ray absorptiometry-measured percentage of body fat (BF\%) of male and female domestic shorthair colony cats in a 1997 study and indoor-confined, adult neutered domestic shorthair pet cats (20II) with a BCS of 4-9 assigned on the basis of visual and palpatory evaluation and use of a 9-point BCS

\begin{tabular}{|c|c|c|c|c|c|c|c|c|}
\hline \multirow[t]{3}{*}{ BCS } & \multicolumn{4}{|c|}{ Male } & \multicolumn{4}{|c|}{ Female } \\
\hline & \multicolumn{2}{|c|}{1997} & \multicolumn{2}{|c|}{2011} & \multicolumn{2}{|c|}{1997} & \multicolumn{2}{|c|}{2011} \\
\hline & $\mathbf{n}$ & BF\% & $\mathbf{n}$ & BF\% & $\mathbf{n}$ & BF\% & $\mathbf{n}$ & BF\% \\
\hline 4 & 4 & $19.8 \pm 4.7$ & 0 & - & 0 & - & 2 & $21.4 \pm 0.5$ \\
\hline 5 & 10 & $21.8 \pm 1.7$ & 8 & $30.1 \pm 4.1$ & 0 & - & 10 & $31.6 \pm 4.6$ \\
\hline 6 & 9 & $28.7 \pm 3.8$ & 7 & $34.6 \pm 2.1$ & I & 42.8 & 10 & $39.3 \pm 4.8$ \\
\hline 7 & 5 & $36.9 \pm 5.4$ & 5 & $41.8 \pm 5.9$ & 4 & $44.1 \pm 1.3$ & 9 & $42.3 \pm 3.9$ \\
\hline 8 & 4 & $39.2 \pm 5.9$ & 14 & $46.9 \pm 3.8$ & 6 & $47.4 \pm 2.1$ & 4 & $48.6 \pm 3.2$ \\
\hline 9 & 0 & - & I & 49.0 & 5 & $53.4 \pm 2.9$ & 3 & $50.7 \pm 4.1$ \\
\hline
\end{tabular}

Note: Copyright $\odot 201$ I. Modified with permisison from Bjornvad CR, Nielsen DH, Armstrong J, et al. Evaluation of a nine-point body condition scoring system in physically inactive pet cats. American Journal of Veterinary Research. 201 I;72:433-437. ${ }^{4}$ Abbreviation: BCS, body-condition score. client-owned cats were all neutered, strictly indoor-dwelling domestic shorthaired cats. ${ }^{4,53}$ We hypothesized that the difference in $\mathrm{BF} \%$ for a given $\mathrm{BCS}$ could be explained by the client-owned cats being sedentary and thus having less muscle mass compared with colony cats. ${ }^{5}$ Less muscle mass would result in a relatively higher $\mathrm{BF} \%$ despite the cats having similar sizes of fat depots.

The use of different DXA hardware and software systems or differences in BCS scoring technique by individual researchers could also be part of the reason for the reported differences in $\mathrm{BF} \%$. In previous studies, however, both intraobserver coefficient of variation (CV; 8.1\%) and interobserver CV (11.6\%-15\%) were relatively low for BCS scoring. ${ }^{53,55}$

When using the BCS, it should be taken into account that neuter status and activity level may affect the conversion of $\mathrm{BCS}$ into $\mathrm{BF} \%$. Still, the BCS is a valuable tool for assessing and monitoring body condition in the individual cat, especially because it is very easy to use in the clinical setting, is illustrative, and repeatable. An important note, however, is that extremely obese cats far exceed the general definition of the 9-point scale, and cats with a BCS of 9 may display a wide range of $\mathrm{BF} \%$.

\section{Feline body mass index}

A feline body mass index (FBMI) is proposed based on measurements of ribcage circumference at the level of the ninth rib and the distance between the patella and calcaneal tuber on the left posterior limb. ${ }^{1,55}$ Hawthorne and Butterwick report that this method was a stronger predictor of $\mathrm{BF} \%$ measured by DXA $\left(r^{2}=0.85\right)$ than BCS $\left(r^{2}=0.73\right)$. The FBMI also acceptably correlated $\left(r^{2}=0.541, P<0.001\right)$ with $\mathrm{BW} .{ }^{56} \mathrm{We}$ found a good correlation between $\mathrm{BF} \%$ estimated by FBMI and by DXA ( $r^{2}=0.90$, unpublished data). It was noted, however, that the measurements could vary a few centimeters depending on the cooperation from the cat. According to the FBMI instructions, the cat should be in a standing position, with legs perpendicular to the table and head in an upright position. ${ }^{1}$ This pose may, in our experience, be difficult to achieve, making the FBMI less practical in practice settings.

\section{Hill's healthy weight protocol}

A new set of morphometric equations has been proposed by Hill's Pet Nutrition (Topeka, KS, USA) in collaboration with the University of Tennessee. This involves six measurements in the cat: head circumference, thoracic circumference, front leg circumference, front leg length, hind leg length, and body length. When entered into an online program, an estimate of $\mathrm{BF} \%$ and ideal $\mathrm{BW}$ is obtained. Alternatively, 
the cat can be categorized according to six illustrations and written descriptions. The cat is placed in one of six BF index (BFI) categories (BFI 20, 30, 40, 50, 60, and 70) representing estimated $\mathrm{BF} \%$. The ideal $\mathrm{BW}$ is then estimated from a chart based on the current weight and BFI category. ${ }^{57}$ Witzel states that this method has a higher correlation and agreement with DXA than the traditional BCS method, and that it is suitable for cats that are extremely obese. This method is currently only presented in abstract form, and the underlying assumptions and algorithm cannot be evaluated objectively.

\section{Assessment by the owner}

Many owners are unable to assess the degree of obesity in their cat correctly, and tend to underestimate the BCS, especially in overweight or obese cats. ${ }^{10,12,14}$ Underestimation of the cat's BCS by the owner is correlated with an increased risk of obesity. ${ }^{12}$ This highlights the veterinarian's role in identifying overweight cats in the clinic and raising awareness of the problem to the owner. The owners should be educated in using the BCS system, thereby increasing the chance of detecting early signs of overweight. An increased awareness of BCS might also increase owner motivation during a weight-loss program.

\section{Weight-loss management in the clinical setting}

Weight-loss plans in cats should be individually tailored, with current feeding, ability to increase physical activity, and owner motivation taken into account. The weight-loss plan should include the following steps: 1) estimation of ideal or target BW (TBW), 2) determining necessary energy restriction, 3) diet selection, 4) feeding management and activity plans, and 5) scheduled follow-up visits, as recommended in the 2014 American Animal Hospital Association (AAHA) weight-management guidelines. ${ }^{58}$

\section{Estimating the target body weight}

Most weight-loss plans include an estimation of TBW. This part of the weight-loss plan can be particularly challenging, and it is often necessary to adjust along the way. A preferred method is using data from the cat's medical records, if these include a BW from a time when the BCS was assessed as ideal. ${ }^{58}$ Another possibility is to combine the current BW and BCS (9-point scale). According to the initial validation, each unit increase in BCS above ideal approximates an increase in BW of 10\%-15\% compared with ideal. ${ }^{53,59}$ Therefore, a cat with a BCS of $7 / 9$ is approximately $20 \%-30 \%$ above ideal weight. BCS scoring is however imprecise in extremely obese cats, and the BFI may prove to be a useful supplement by embracing this category of cats. ${ }^{57}$

\section{Determining energy restriction}

The carnivorous cat has a unique metabolism and depends on high daily protein allowances. In obese cats, energy restriction may lead to severe protein restriction and increased lipid mobilization, which can lead to the development of hepatic lipidosis. ${ }^{60,61}$ An energy restriction to $50 \%$ of metabolic energy requirement (MER) has been estimated to be safe in cats. ${ }^{62}$ Still, in a weight-loss study with clientowned cats being restricted to $60 \%$ of MER (30 kcal/TBW/ day), one cat developed hepatic lipidosis. ${ }^{61}$ The authors did not discuss whether the hepatic lipidosis was a result of the energy restriction or because the cat had refused to eat the diet. Still, it emphasizes the importance of regular follow-up visits to evaluate weight-loss progression and necessary adjustments.

Generally, weight loss in cats should aim at a rate of $0.5 \%-2 \%$ of initial BW per week resulting in an anticipated duration for reaching TBW of 24-60 weeks in a cat that needs to lose $3 \mathrm{~kg} \mathrm{BW} .^{58}$ Slow weight loss may preserve lean body mass at the expense of fat, and thereby maintain metabolically active tissue. ${ }^{35}$

Few studies have evaluated weight-loss programs in client-owned cats; results indicate that the required level of energy restriction is higher than reported for colony cats. One study reported a mean weight loss of $0.8 \%$ per week with an initial energy allocation of $41 \mathrm{kcal} / \mathrm{TBW} /$ day, which was further reduced to $27 \mathrm{kcal} / \mathrm{TBW} /$ day during the study. ${ }^{63}$ In another study, a mean energy allowance of 29-32 kcal/ TBW/day resulted in a weight loss of $0.55 \%$ per week. ${ }^{61}$ The AAHA recommends an energy requirement of $80 \%$ of resting energy requirement, which yields an estimate of 37.5 or $39.5 \mathrm{kcal} / \mathrm{TBW} /$ day, for a 5 or $4 \mathrm{~kg}$ TBW, respectively. ${ }^{58}$ The lower energy requirement in client-owned cats may be caused by a low level of physical activity compared to colony cats, or it could reflect a shortage in client compliance (eg, not giving the correct amount of food as instructed).

Some owner-animal relations rely on treats, and it may be hard for owners to adhere strictly to the weight-loss plan. ${ }^{64}$ To optimize owner compliance, treats should be allowed in a limited amount and calculated as part of the daily caloric ration.

Another good way to determine energy restriction for a weight-loss plan is to calculate the current energy allocation, based on a detailed food diary for a 2 -week period. The recommended energy allowance is then calculated as $80 \%$ of current intake. ${ }^{58}$ 


\section{Diet selection}

By feeding a food designed for weight loss, the risk of malnutrition is minimized. Maintenance diets are balanced for essential nutrients in relation to the energy density of the diet. When the daily energy allowance is restricted, all other nutrients will be restricted similarly and could result in deficiencies. Weight-loss diets have a higher nutrient:energy ratio to secure an adequate intake of essential nutrients despite energy restriction. Most weight-loss diets for cats have increased protein, low fat, low-to-moderate carbohydrate, and increased fiber content. Fiber is categorized as soluble and insoluble. In the ingredient list, crude fiber generally includes insoluble fiber, while the soluble fiber fraction is included in the carbohydrate fraction. The actual fiber content may therefore be difficult to determine. Also, the energy content of the carbohydrate fraction may be overestimated if there is a high content of soluble fiber. High-protein diets are often recommended, and may decrease the loss of lean mass compared with moderate-protein diets. Cats have no essential need for carbohydrates, and it has been hypothesized that carbohydrates could predispose them to impaired glucose tolerance. ${ }^{65}$ Several studies have compared high-protein (HP)/low-carbohydrate (LC) and low-protein (LP)/high-carbohydrate (HC) diets, and the results are inconsistent. ${ }^{66-68}$ Some found a lower postprandial glucose response with $\mathrm{HP} / \mathrm{LC}$, while other investigators failed to reproduce this difference. ${ }^{35,66,69,70}$ Interestingly, a recent study indicated that cats fed an HP/LC diet tended to eat more than cats fed an LP/HC diet, which could result in weight gain. The optimal amount of protein and fiber and optimal type of fiber is still unknown, but is generally recommended to increase both nutrients in weight-loss diets to support satiety and preserve lean body mass. The diet should provide the cat with at least $5 \mathrm{~g}$ protein per kilogram TBW daily. ${ }^{58} \mathrm{~A}$ gradual transition is recommended to increase the chance of the cat accepting the new food and also adjust to the lower energy allowance.

\section{Commercial weight-loss diets for cats}

Table 3 gives an overview of selected prescription weight-loss diets. The diets are compared with respect to macronutrients on a dry-matter (DM) basis and on an energy basis. Due to variations in labeling, the carbohydrate level in some diets is

Table 3 Energy and macronutrient content (protein, fat, carbohydrate [CHO], and fiber) in selected weight-loss products sold through veterinarians, either based on per dry matter (DM) or per $100 \mathrm{kcal}$ metabolizable energy (ME)

\begin{tabular}{|c|c|c|c|c|c|c|c|c|c|}
\hline \multirow[t]{3}{*}{ Diet } & \multirow[t]{3}{*}{ Form } & \multicolumn{5}{|c|}{ Dry matter } & \multicolumn{3}{|c|}{ Per 100 kcal } \\
\hline & & Energy & Protein & Fat & СHO & Fiber & Protein & Fat & $\mathrm{CHO}$ \\
\hline & & $\overline{\mathrm{kcal} / \mathrm{kg}}$ & $\%$ & $\%$ & $\%$ & $\%$ & $\mathbf{g}$ & $\mathbf{g}$ & $\mathbf{g}$ \\
\hline \multicolumn{10}{|c|}{ Weight loss } \\
\hline 1 & Dry & 3,365 & 39.0 & 110 & 30.2 & 13.7 & 11.6 & 3.3 & 9.0 \\
\hline 2 & Dry & 3,566 & 40.0 & 12.8 & 30.9 & 9.8 & 11.2 & 3.6 & 8.7 \\
\hline 3 & Dry & 3,584 & 45.7 & 10.9 & $33.9^{\#}$ & 7.2 & 12.7 & 3.0 & $9.5^{\#}$ \\
\hline 4 & Dry & 3,174 & 37.0 & 9.8 & $35.5^{\#}$ & 15.3 & 11.6 & 3.1 & $11.2^{\#}$ \\
\hline 5 & Dry & $3,712^{\#}$ & 39.8 & 10.3 & 41.2 & 1.7 & 10.7 & 2.8 & 11.1 \\
\hline 6 & Dry & 3,640 & $56.2^{*}$ & $9.0^{*}$ & $23.9^{\#}$ & $8.4^{\S}$ & $15.4^{*}$ & $2.5^{*}$ & $6.6^{\#}$ \\
\hline \multicolumn{10}{|c|}{ Diabetic } \\
\hline 7 & Dry & 4,203 & 50.0 & 13.0 & 29.0 & 3.9 & 11.9 & 3.1 & 6.9 \\
\hline 8 & Dry & 4,160 & 50.5 & 20.0 & 19.8 & 3.8 & 12.1 & 4.8 & 4.8 \\
\hline 9 & Dry & 4,680 & $58.0 *$ & $17.0 *$ & $20.5^{\#}$ & $3.4^{\S}$ & $12.4^{*}$ & $3.6^{*}$ & $4.4^{\#}$ \\
\hline \multicolumn{10}{|c|}{ Weight loss } \\
\hline 1 & Canned & 3,195 & 37.3 & 9.1 & 31.5 & 15.4 & 11.7 & 2.9 & 9.9 \\
\hline 2 & Canned & 3,574 & 39.1 & 12.8 & 31.5 & 10.2 & 11.0 & 3.6 & 8.8 \\
\hline 3 & Canned & 3,381 & 46.9 & 12.5 & $28.8^{\#}$ & 9.4 & 13.9 & 3.7 & $8.5^{\#}$ \\
\hline 5 & Canned & 5,217 & 45.7 & 19.6 & 20.9 & 7.0 & 8.8 & 3.8 & 4.0 \\
\hline 6 & Canned & 4,115 & $42.5^{*}$ & $5.0^{*}$ & $24.5^{\#}$ & $20.0^{\S}$ & $10.3^{*}$ & $1.2^{*}$ & $6.0^{\#}$ \\
\hline \multicolumn{10}{|c|}{ Diabetic } \\
\hline 8 & Canned & 4,073 & 52.8 & 19.4 & 10.1 & 6.0 & 13.0 & 4.8 & 2.5 \\
\hline 9 & Canned & 5,577 & $52.3^{*}$ & $20.5^{*}$ & $0.0^{\#}$ & $9.1^{\S}$ & $9.4^{*}$ & $3.7^{*}$ & $0.0^{\#}$ \\
\hline
\end{tabular}

Notes: *Minimum level; ' maximum level; "estimated value. I, Hills Prescription Diet r/d Feline Weight loss - Low calorie (Hill's Pet Nutrition, Topeka, KS, USA); 2 , Hills Prescription Diet Feline Metabolic Advanced Weight Solution (Hill's Pet Nutrition, Topeka, KS, USA); 3, Royal Canin Obesity Management (Royal Canin, Inc, St. Charles, MO, USA); 4, Royal Canin Satiety Support (Royal Canin, Inc, St. Charles, MO, USA); 5, Eukanuba Restricted Calorie (Eukanuba, The Procter \& Gamble Company, Cincinnati, OH, USA); 6, Purina Overweight Management (Purina Veterinary Diets, Nestlé Purina, Wilkes-Barre, PA, USA); 7, Royal Canin Diabetic (Royal Canin, Inc, St. Charles, MO, USA); 8, Hill's Prescription Diet m/d Weight loss - Low carbohydrate - Glucose management (Hill's Pet Nutrition, Topeka, KS, USA); 9, Purina DM Dietetic Management ${ }^{\circledR}$ (Purina Veterinary Diets, Nestlé Purina, Wilkes-Barre, PA, USA). Information from Hill's Key to Nutrition 2013, Product Book (Aimargues, France: Royal Canin; 2013), http://www.eukanuba.co.uk, and http://www.purinaveterinarydiets.com. 
estimated based on the available information. Energy levels in the dry weight-loss diets (3,174-3,712 kcal/kg DM) are lower than the energy levels in the dry diabetic/weight-management diets $(4,160-4,680 \mathrm{kcal} / \mathrm{kg}$ DM). Energy levels in the canned weight-loss diets vary more $(3,195-5,217 \mathrm{kcal} / \mathrm{kg} \mathrm{DM})$ and reach the levels of diabetic/weight-management canned diets $(4,073-5,577 \mathrm{kcal} / \mathrm{kg} \mathrm{DM})$. For weight loss, the daily recommended portion sizes for dry weight-loss diets were 49-81 g and for canned diets 171-292 g, yielding an energy allowance that differed from the AAHA weightmanagement recommendations from between 14\% less per day to $39 \%$ more (Table 4). A previous study found similar discrepancies. ${ }^{71}$ Additionally, the National Research Council states that energy requirements of individual cats may be over- or underestimated by more than $50 \%$ using recommended calculations. ${ }^{72}$ Optimal methods for determining both individual energy needs and the energy content of a pet food are still being debated. Veterinarians should be aware of this discourse, and inform owners that the daily food allowance initially recommended is based on a rough estimate and will likely need to be adjusted. One company provides recommendations for a phase 3 weight-loss allowance. These recommendations, however, result in the cat being restricted to $37 \%$ of the energy allowance recommended by the AAHA for weight loss, which could lead to an increased risk of developing hepatic lipidosis.

\section{Feeding management and activity plan Measuring cup or scale?}

Measuring cups can have poor precision both between (CV 2\%-28\%) and within (CV 2\%-15\%) subjects using the cups, and also low accuracy (from an underestimation of $18 \%$ to an overestimation of $80 \%) .{ }^{73}$ Inaccuracy was greatest for smaller portions, which tended to be overestimated. Also, in four of six cups marked with a graded scale by the manufacturer, the grading was inaccurate, leading to a portion size up to $40 \%$ bigger than expected. ${ }^{73}$ We recommend using a kitchen

Table 4 Recommended portion size and daily energy allowance according to product declarations compared to American Animal Hospital Association (AAHA) 2014 recommendations for weight loss $\left(0.8 *\left(70 *\right.\right.$ target body weight $\left.\left.{ }^{0.75}\right)\right)$ and National Research Council (NRC) 2006 recommendations for maintenance in overweight cats (I30*body weight ${ }^{0.4}$ )

\begin{tabular}{|c|c|c|c|c|c|c|c|}
\hline \multirow[t]{3}{*}{ Diet } & \multirow[t]{3}{*}{ Form } & \multicolumn{3}{|c|}{ Weight loss } & \multicolumn{3}{|c|}{ Maintenance } \\
\hline & & \multirow{2}{*}{$\begin{array}{l}\text { Portion } \\
\text { size } \\
\text { (g/day) }\end{array}$} & \multirow{2}{*}{$\begin{array}{l}\text { Energy } \\
\text { kcal/day }\end{array}$} & \multirow{2}{*}{$\begin{array}{l}\text { Difference to } \\
\text { AAHA 20I4 } \\
\%\end{array}$} & \multirow{2}{*}{$\begin{array}{l}\text { Portion } \\
\text { size } \\
\text { g/day }\end{array}$} & \multirow{2}{*}{$\begin{array}{l}\text { Energy } \\
\text { kcal/day }\end{array}$} & \multirow{2}{*}{$\begin{array}{l}\text { Difference to } \\
\text { NRC } 2006 \\
\%\end{array}$} \\
\hline & & & & & & & \\
\hline $\mathrm{AAHA}$ & - & - & 187.5 & - & - & - & - \\
\hline NRC 2006 & - & - & - & - & - & 248 & - \\
\hline 1 & Dry & 55 & 175 & -7 & 88 & 278 & 12 \\
\hline 2 & Dry & 55 & 185 & -1 & 80 & 270 & 9 \\
\hline 3 & & 49 & 162 & -14 & 78 & 257 & 4 \\
\hline 4 & Dry & 57 & 166 & -11 & 89 & 260 & 5 \\
\hline 5 & Dry & 50 & 174 & -7 & 75 & 261 & 5 \\
\hline 6 & Dry & 81 & 261 & 39 & 93 & 301 & 22 \\
\hline \multicolumn{8}{|l|}{ HP } \\
\hline 7 & Dry & 50 & 193 & 3 & 63 & 244 & -2 \\
\hline 8 & Dry & 48 & 186 & -1 & 73 & 283 & 14 \\
\hline 9 & Dry & NA & NA & - & 72 & 296 & 20 \\
\hline I & Canned & 234 & 180 & -4 & 370 & 285 & 15 \\
\hline 2 & Canned & 234 & 197 & 5 & 312 & 262 & 6 \\
\hline 3 & Pouch & 370 & 200 & 7 & 510 & 276 & II \\
\hline 5 & Canned & $|7|$ & 206 & 10 & 227 & 272 & 10 \\
\hline 6 & Canned & 292 & 240 & 28 & 360 & 296 & 19 \\
\hline \multicolumn{8}{|l|}{$\mathrm{HP}$} \\
\hline 8 & Canned & 182 & 184 & -2 & 273 & 276 & 11 \\
\hline 9 & Canned & NA & NA & - & 234 & 287 & 16 \\
\hline
\end{tabular}

Notes: Calculations are based on a cat with a target weight of 5 kg. I, Hills Prescription Diet r/d Feline Weight loss - Low calorie (Hill's Pet Nutrition, Topeka, KS, USA); 2, Hills Prescription Diet Feline Metabolic Advanced Weight Solution (Hill's Pet Nutrition, Topeka, KS, USA); 3, Royal Canin Obesity Management (Royal Canin, Inc, St Charles, MO, USA); 4, Royal Canin Satiety Support (Royal Canin, Inc, St Charles, MO, USA); 5, Eukanuba Restricted Calorie (Eukanuba, The Procter \& Gamble Company, Cincinnati, OH, USA); 6, Purina Overweight Management (Purina Veterinary Diets, Nestlé Purina, Wilkes-Barre, PA, USA); 7, Royal Canin Diabetic (Royal Canin, Inc, St Charles, MO, USA); 8, Hill's Prescription Diet m/d Weight loss - Low carbohydrate - Glucose management (Hill's Pet Nutrition, Topeka, KS, USA); 9, Purina DM Dietetic Management ${ }^{\circledR}$ (Purina Veterinary Diets, Nestlé Purina, Wilkes-Barre, PA, USA). Information from Hill's Key to Nutrition 20I3, Product Book (Aimargues, France: Royal Canin; 2013), http://www.eukanuba.co.uk, and http://www.purinaveterinarydiets.com.

Abbreviations: NA, not applicable; HP, high protein. 
scale for measuring out food portions, since unintentional overfeeding could predispose cats to weight gain.

Daily physical activity should be increased, eg, by making the cat work for the food by changing the location of the food bowl, placing food in difficult-to-access places, or feeding with an activity toy. ${ }^{74}$ Several websites offer ideas for increasing activity in cats. ${ }^{74}$

\section{Increasing the chance of a successful weight-loss program}

Currently, there is little knowledge on the effect of regular follow-up and long-term outcome of feline weight-loss programs. However, experts in the field recommend regular monitoring to increase the chance of success. ${ }^{58}$ At rechecks, the feeding allowance is adjusted by $\pm 10 \%$ based on weight change. ${ }^{58}$ If weight loss is insufficient, reassess the plan, assess owner compliance, and if adherence is verified, the calorie allowance is decreased.$^{58} \mathrm{~A}$ recent study monitored 26 cats for a period of 2 months to 6 years following a successful weight-loss program. Forty-six percent regained weight, and $27 \%$ regained more than $50 \%$ of the weight lost. ${ }^{75}$ Timing of regain, follow-up intervals, and the maintenance-feeding regime were not specified. Still, regain appears to be common even after successful weight loss, comparable to findings in dogs. ${ }^{76}$ In dogs, MER decreased after weight loss, and a long-term reduction in daily caloric intake was necessary to prevent weight regain. ${ }^{77,78}$ This may be true in cats too, but further studies are needed.

The owner-cat relationship may also influence the chance of success. In one study, more owners of obese cats had acquired the cat as a way to increase their own happiness and to have a companion compared to owners of normal-weight cats. ${ }^{64}$ Owners of overweight cats also had a greater tendency to watch their cat eat, and felt that their cat preferred food over play as a treat. This may not pertain to all cat owners, but is important to consider when designing a weight-loss plan. Owners should be educated in other ways to interact with their cat than by providing treats or food. In our experience, owners often feel their cat is constantly hungry and begging for food (vocalizing or pawing the owner), which challenges their ability to adhere to the weight-loss plan. Owners should be aware that it is often an acquired behavior, and that it takes time and patience to change. ${ }^{58}$

\section{Medical management of obesity}

Currently, there are no approved drugs for weight loss in cats. In recent years, the glucagon-like peptide (GLP)-1 analogs liraglutide (Victoza ${ }^{\circledR}$; Novo Nordisk, Bagsvaerd, Denmark) and exenatide (Byetta ${ }^{\circledR}$; Eli Lilly, Indianapolis, IN, USA) have gained interest as possible weight-loss agents in humans. Both drugs are currently approved for the treatment of type 2 diabetes in humans, and exert an antidiabetic effect by various mechanisms, including stimulation of insulin production, suppression of glucagon production, prevention of $\beta$-cell exhaustion, and apoptosis. ${ }^{79-81}$ Several studies have shown a weight-loss effect in both diabetic and nondiabetic human subjects, and the majority of patients maintained the weight loss over time. ${ }^{80,82-84}$ GLP-1 analogs could prove useful in obese feline patients, helping them to lose weight and improving their metabolic status. Short-term studies in normal-weight cats have shown that GLP-1 analogs are well tolerated by cats and increase insulin secretion. ${ }^{85,86}$ Long term effects on insulin secretion and BW are currently unknown.

\section{Prevention of obesity}

Adhering to weight-loss programs is hard work, and owner motivation may decline. Prevention of obesity is therefore of great importance in veterinary practice. Early detection of increasing BW allows the owner to make appropriate adjustments and prevent further progression. However, obesity has a gradual onset and progression, and in our experience few owners regularly monitor their cat's BW. Unfortunately, a study in dogs showed that BW and body condition were inconsistently recorded in veterinary practice. ${ }^{87}$ Likewise in cats, even when the veterinarian did assess the body condition of a cat, a diagnosis of obese or overweight was rarely recorded. ${ }^{9}$ This could indicate that veterinarians do not regard overweight or obesity as a disease or problem equivalent to other types of disease. A lack of regular body-condition scoring may increase the risk of late recognition of obesity. ${ }^{88}$ In order to prevent obesity in cats, the veterinarian should recognize early signs of overweight, register the BCS and BW regularly, and inform the owners of the condition, risks, and management.

\section{Conclusion}

Obesity is common in client-owned cats and increases the risk of several diseases. Weight-loss programs require persistent owner dedication, and emphasis should be on prevention of the development of obesity. The BCS is a simple and reliable tool for assessing obesity in the clinic; it should be used regularly, and the results logged in the medical record. Ideal BW may be estimated from current BCS or possibly by the recently introduced BFI system. Studies indicate that approximately $39 \mathrm{kcal} / \mathrm{kg}$ TBW is an appropriate initial daily caloric allowance for obese cats in a weight-loss program. Regular follow-up visits are recommended to maintain owner motivation and to make appropriate adjustments in caloric intake 
based on progress. Several weight-loss diets are available, and these are preferred over maintenance diets for weight loss to ensure adequate intake of essential nutrients. Most weightloss diets have an increase in either protein or fiber content or a combination of these. The optimal diet composition for weight loss is still debated, and the choice of diet should be tailored for the individual cat. The energy requirement for cats is difficult to calculate, and owners should be made aware that several adjustments are often needed and that successful weight-loss programs require long-term motivation and willingness to adapt to new routines at home.

\section{Disclosure}

The authors report no conflicts of interest in this work.

\section{References}

1. Butterwick R. How fat is that cat? J Feline Med Surg. 2000;2:91-94.

2. Janssen I, Katzmarzyk PT, Ross R, et al. Fitness alters the associations of BMI and waist circumference with total and abdominal fat. Obes Res. 2004;12:525-537.

3. Romero-Corral A, Somers VK, Sierra-Johnson J, et al. Normal weight obesity: a risk factor for cardiometabolic dysregulation and cardiovascular mortality. Eur Heart J. 2010;31:737-746.

4. Bjornvad CR, Nielsen DH, Armstrong J, et al. Evaluation of a nine-point body condition scoring system in physically inactive pet cats. Am J Vet Res. 2011;72:433-437.

5. Cline MG, Witzel AL, Moyers TD, Bartges JW, Kirk CA. Body composition of outdoor-intact cats compared to indoor-neutered cats using dual energy X-ray absorptiometry. In: Proceedings of the 17th European Society of Veterinary and Comparative Nutrition Congress. Belgium: University Press; 2013:51.

6. Russell K, Sabin R, Holt S, Bradley R, Harper EJ. Influence of feeding regimen on body condition in the cat. J Small Anim Pract. 2000;41: $12-17$.

7. Sloth C. Practical management of obesity in dogs and cats. $J$ Small Anim Pract. 1992;33:178-182.

8. Scarlett JM, Donoghue S, Saidla J, Wills J. Overweight cats: prevalence and risk factors. Int J Obes Relat Metab Disord. 1994;18 Suppl 1: S22-S28.

9. Lund EM, Armstrong J, Kirk CA, Klausner JS. Prevalence and risk factors for obesity in adult cats from private US veterinary practices. Int J Appl Res Vet Med. 2005;3:88-96.

10. Courcier EA, Mellor DJ, Pendlebury E, Evans C, Yam PS. An investigation into the epidemiology of feline obesity in Great Britain: results of a cross-sectional study of 47 companion animal practises. Vet Rec. 2012;171:560-564.

11. Häring T, Wichert B, Dolf G, Haase B. Segregation analysis of overweight body condition in an experimental cat population. $J$ Hered. 2011;102 Suppl 1:S28-S31.

12. Colliard L, Paragon BM, Lemuet B, Bénet JJ, Blanchard G. Prevalence and risk factors of obesity in an urban population of healthy cats. J Feline Med Surg. 2009;11:135-140.

13. Corbee RJ. Obesity in show cats. In: Proceedings of the 17th European Society of Veterinary and Comparative Nutrition Congress. Belgium: University Press; 2013:106.

14. Courcier EA, O'Higgins RO, Mellor DJ, Yam PS. Prevalence and risk factors for feline obesity in a first opinion practice in Glasgow, Scotland. $J$ Feline Med Surg. 2010;12:746-753.

15. Flynn MF, Hardie EM, Armstrong PJ. Effect of ovariohysterectomy on maintenance energy requirement in cat. JAm Vet Med Assoc. 1996;209: $1572-1581$.
16. Fettman MJ, Stanton CA, Banks LL, Hamar DW. Effects of neutering on bodyweight, metabolic rate and glucose tolerance of domestic cats. Res Vet Sci. 1997;62:131-136.

17. Kanchuk ML, Backus RC, Calvert CC, Morris JG, Rogers QR. Weight gain in gonadectomized normal and lipoprotein lipase-deficient male domestic cats results from increased food intake and not decreased energy expenditure. $J$ Nutr. 2003;133:1866-1874.

18. Martin G, Rand JS. Pharmacology of a $40 \mathrm{IU} / \mathrm{mL}$ porcine lente insulin preparation in diabetic cats: findings during the first week and after 5 or 9 weeks of therapy. J Feline Med Surg. 2001;3:23-30.

19. Belsito KR, Vester BM, Keel T, Graves TK, Swanson KS. Impact of ovariohysterectomy and food intake on body composition, physical activity, and adipose gene expression in cats. J Anim Sci. 2009;87:594-602.

20. Harper EJ, Stack DM, Watson TD, Moxham G. Effects of feeding regimens on bodyweight, composition and condition score in cats following ovariohysterectomy. J Small Anim Pract. 2001;42:433-438.

21. Hoenig M, Ferguson DC. Effects of neutering on hormonal concentrations and energy requirements in male and female cats. Am J Vet Res. 2002;63:634-639.

22. Allaway D, Gilham M, Colyer A, Jonsson T, Swanson K, Morris PJ. Effects of puberty and timing of gonadectomy on the plasma metabolome of young cats. In: The Waltham International Nutritional Sciences Symposium 2013: From Pet Food to Pet Care - Bridging the Gap. McLean (VA): Mars:59.

23. Kershaw EE, Flier JS. Adipose tissue as an endocrine organ. J Clin Endocrinol Metab. 2004;89:2548-2556.

24. Ouchi N, Parker JL, Lugus JJ, Walsh K. Adipokines in inflammation and metabolic disease. Nat Rev Immunol. 2011;11:85-97.

25. Prahl A, Guptill L, Glickman NW, Tetrick M, GLickman LT. Time trends and risk factors for diabetes mellitus in cats presented to veterinary teaching hospitals. J Feline Med Surg. 2007;9:351-358.

26. McCann TM, Simpson KE, Shaw DJ, Butt JA, Gunn-Moore DA. Feline diabetes mellitus in the UK: the prevalence within an insured cat population and a questionnaire-based putative risk factor analysis. J Feline Med Surg. 2007;9:289-299.

27. Scarlett JM, Donoghue S. Associations between body condition and disease in cats. J Am Vet Med Assoc. 1998;212(11):1725-1731.

28. Henson MS, O'Brien TD. Feline models of type 2 diabetes mellitus. ILAR J. 2006;47:234-242.

29. Osto M, Zini E, Reusch CE, Lutz TA. Diabetes from humans to cats Gen Comp Endocrinol. 2013;182:48-53.

30. Brennan CL, Hoenig M, Ferguson DC. GLUT4 but not GLUT1 expression decreases early in the development of feline obesity. Domest Anim Endocrinol. 2004;26:291-301.

31. Wilkins C, Long RC Jr, Waldron M, Ferguson DC, Hoenig M. Assessment of the influence of fatty acids on indices of insulin sensitivity and myocellular lipid content by use of magnetic resonance spectroscopy in cats. Am J Vet Res. 2004;65:1090-1099.

32. Biourge V, Nelson RW, Feldman EC, Willits NH, Morris JG, Rogers QR. Effect of weight gain and subsequent weight loss on glucose tolerance and insulin response in healthy cats. J Vet Intern Med. 1997;11:86-91.

33. Pottie P, Presle N, Terlain B, Netter P, Mainard D, Berenbaum F. Obesity and osteoarthritis: more complex than predicted! Ann Rheum Dis. 2006;65:1403-1405.

34. Scherer PE. Adipose tissue: from lipid storage compartment to endocrine organ. Diabetes. 2006;55:1537-1545.

35. Hoenig M, Thomaseth K, Waldron M, Ferguson DC. Insulin sensitivity, fat distribution and adipocytokine response to different diets in lean and obese cats before and after weight loss. Am J Physiol Regul Integr Comp Physiol. 2007;292:R227-R234.

36. Van de Velde H, Janssens GPJ, de Rooster H, et al. The cat as a model for human obesity: insights into depot-specific inflammation associated with feline obesity. Br J Nutr. 2013;110:1326-1335.

37. Bjornvad CR, Rand JS, Tan HY, et al. Obesity and sex influence insulin resistance and total and multimer adiponectin levels in adult neutered domestic shorthair client-owned cats. Domest Anim Endocrinol. 2014;14:55-64. 
38. Appleton DJ, Rand JS, Sunvold GD. Plasma leptin concentrations in cats: reference range, effect of weight gain and relationship with adiposity as measured by dual energy X-ray absorptiometry. J Feline Med Surg. 2000;2:191-199.

39. Hoenig M, Pach N, Thomaseth K, Le A, Schaeffer D, Ferguson DC. Cats differ from other species in their cytokine and antioxidant enzyme response when developing obesity. Obesity (Silver Spring). 2013;21: E407-E414.

40. Appleton DJ, Rand JS, Sunvold GD. Plasma leptin concentrations are independently associated with insulin sensitivity in lean and overweight cats. J Feline Med Surg. 2002;4:83-93.

41. Kadowaki T, Yamauchi T, Kubota N, Hara K, Ueki K, Tobe K. Adiponectin and adiponectin receptors in insulin resistance, diabetes, and the metabolic syndrome. J Clin Invest. 2006;116:1784-1792.

42. Muranaka S, Mori N, Hatano Y, et al. Obesity induced changes to plasma adiponectin concentration and cholesterol lipoprotein composition profile in cats. Res Vet Sci. 2011;91:358-361.

43. Ishioka K, Omachi A, Sasaki N, Kimura K, Saito M. Feline adiponectin: molecular structures and plasma concentrations in obese cats. JVet Med Sci. 2009;71:189-194.

44. Tan HY, Rand JS, Morton JM, et al. Adiponectin profiles are affected by chronic and acute changes in carbohydrate intake in healthy cats. Gen Comp Endocrinol. 2011;172:468-474.

45. Tvarijonaviciute A, Ceron JJ, Holden SL, Morris PJ, Biourge V, German AJ. Effects of weight loss in obese cats on biochemical analytes related to inflammation and glucose homeostasis. Domest Anim Endocrinol. 2012;42:129-141.

46. Hoenig M, McGoldrick JB, DeBeer M, Demacker PN, Ferguson DC. Activity and tissue-specific expression of lipases and tumor-necrosis factor alpha in lean and obese cats. Domest Anim Endocrinol. 2006;30: 333-344.

47. Miller C, Bartges J, Cornelius L, Norton N, Barton M. Tumor necrosis factor- $\alpha$ levels in adipose tissue of lean and obese cats. J Nutr. 1998;128: 2751S-2752S.

48. Ul-Haq Z, Mackay DF, Fenwick E, Pell JP. Meta-analysis of the association between body mass index and health-related quality of life among adults, assessed by the SF-36. Obesity (Silver Spring). 2013; 21(3):E322-E327.

49. German AJ, Holden SL, Wiseman-Orr ML, et al. Quality of life is reduced in obese dogs but improves after successful weight loss. Vet J. 2012;192:428-434.

50. Munday HS, Booles D, Anderson P, Poore DW, Earle KE. The repeatability of body composition measurements in dogs and cats using dual energy X-ray absorptiometry. J Nutr. 1994;124:2619S-2621S.

51. Lauten SD, Cox NR, Baker GH, Painter DJ, Morrison NE, Baker HJ. Body composition of growing and adult cats as measured by use of dual energy X-ray absorptiometry. Comp Med. 2000;50(2): $175-183$.

52. Kienzle E, Moik K. A pilot study on the body weight of pure-bred client-owned adult cats. Br J Nutr. 2011;106:S113-S115.

53. Laflamme D. Development and validation of a body condition score system for cats: a clinical tool. Feline Pract. 1997;25:13-18.

54. German AJ, Holden SL, Moxham GL, Holmes KL, Hackett RM, Rawlings JM. A simple, reliable tool for owners to assess the body condition of their dog or cat. J Nutr. 2006;136:2031S-2033S.

55. Hawthorne A, Butterwick RF. Predicting the body composition of cats: development of a zoometric measurement for estimation of percentage body fat in cats [abstract]. J Vet Intern Med. 2000;14:365.

56. Hoenig M, Traas AM, Schaeffer DJ. Evaluation of routine hematology profile results and fructosamine, thyroxine, insulin, and proinsulin concentrations in lean, overweight, obese, and diabetic cats. $J$ Am Vet Med Assoc. 2013;243:1302-1309.

57. Witzel A. What can we learn from DEXA, BCS, BFI and HWP? Poster presented at: Hill's Global Symposium on Obesity; May 24, 2013; Barcelona.

58. Brooks D, Churchill J, Fein K, et al. 2014 AAHA weight management guidelines for dogs and cats. J Am Anim Hosp Assoc. 2014;50:1-11.
59. Laflamme DP. Nutrition for aging cats and dogs and the importance of body condition. Vet Clin North Am Small Anim Pract. 2005;35: 713-742.

60. Blanchard G, Paragon BM, Sérougne C, Férézou J, Milliat F, Lutton C. Plasma lipids, lipoprotein composition and profile during induction and treatment of hepatic lipidosis in cats and the metabolic effect of one daily meal in healthy cats. J Anim Physiol Anim Nutr (Berl). 2004;88:73-87.

61. Bissot T, Servet E, Vidal S, et al. Novel dietary strategies can improve the outcome of weight loss programmes in obese client-owned cats. J Feline Med Surg. 2010;12:104-112.

62. Dimski DS, Buffington CA, Johnson SE, Sherding RG, Rosol TJ. Serum lipoprotein concentrations and hepatic lesions in obese cats undergoing weight loss. Am J Vet Res. 1992;53:1259-1262.

63. German AJ, Holden S, Bissot T, Morris PJ, Biourge V. Changes in body composition during weight loss in obese client-owned cats: loss of lean tissue mass correlates with overall percentage of weight lost. $J$ Feline Med Surg. 2008;10:452-459.

64. Kienzle E, Bergler R. Human-animal relationship of owners of normal and overweight cats. J Nutr. 2006;136:1947S-1950S.

65. Verbrugghe A, Hesta M, Daminet S, Janssens GP. Nutritional modulation of insulin resistance in the true carnivorous cat: a review. Crit Rev Food Sci Nutr. 2012;52:172-182.

66. Verbrugghe A, Hesta M, Van Weyenberg S, et al. The glucose and insulin response to isoenergetic reduction of dietary energy sources in a true carnivore: the domestic cat (Felis catus). Br J Nutr. 2010;104: 214-221.

67. Coradini M, Rand JS, Morton JM, Rawlings JM. Effects of two commercially available feline diets on glucose and insulin concentrations, insulin sensitivity and energetic efficiency of weight gain. Br J Nutr. 2011;106:S64-S77.

68. Mori A, Sako T, Lee P, et al. Comparison of three commercially available prescription diet regimens on short-term post-prandial serum glucose and insulin concentrations in healthy cats. Vet Res Commun. 2009;33:669-680.

69. Farrow HA, Rand JS, Morton JM, O'Leary CA, Sunvold GD. Effect of dietary carbohydrate, fat, and protein on postprandial glycemia and energy intake in cats. $J$ Vet Intern Med. 2013;27:1121-1135.

70. Leray V, Freuchet B, Le Bloc'h J, Jeusette I, Torre C, Nguyen P. Effect of citrus polyphenol- and curcumin-supplemented diet on inflammatory state in obese cats. Br J Nutr. 2011;106:S198-S201.

71. Linder DE, Freeman LM. Evaluation of caloric density and feeding directions for commercially available diets designed for weight loss in dogs and cats. J Am Vet Med Assoc. 2010;236:74-77.

72. National Research Council. Nutrient Requirements of Dogs and Cats. Washington: National Academies; 2006.

73. German AJ, Holden SL, Mason SL, et al. Imprecision when using measuring cups to weigh out extruded dry kibbled food. JAnim Physiol Anim Nutr. 2011;95:368-373.

74. Michel K, Scherk M. From problem to success: feline weight loss programs that work. J Feline Med Surg. 2012;14:327-336.

75. Deagle G, Holden SL, Biourge V, Morris PJ, German AJ. Long-term outcomes of weight management in obese cats. In: The Waltham International Nutritional Sciences Symposium 2013: From Pet Food to Pet Care - Bridging the Gap. McLean (VA): Mars:49.

76. German AJ, Holden SL, Morris PJ, Biourge V. Long-term follow-up after weight management in obese dogs: the role of diet in preventing regain. Vet J. 2012;192:65-70.

77. German AJ, Holden SL, Mather NJ, et al. Low-maintenance energy requirements of obese dogs after weight loss. Br J Nutr. 2011;106: S93-S96.

78. Nagaoka D, Mitsuhashi Y, Angell R, Bigley KE, Bauer JE. Re-induction of obese body weight occurs more rapidly and at a lower caloric intake in beagles. J Anim Physiol Anim Nutr. 2010;94:287-292.

79. Kreymann B, Williams G, Ghatei MA, Bloom SR. Glucagon-like peptide-1 7-36: a physiological incretin in man. Lancet. 1987;2: $1300-1304$. 
80. Kelly AS, Metzig AM, Rudser KD, et al. Exenatide as a weight-loss therapy in extreme pediatric obesity: a randomized, controlled pilot study. Obesity (Silver Spring). 2012;20:364-370.

81. Kim W, Egan JM. The role of incretins in glucose homeostasis and diabetes treatment. Pharmacol Rev. 2008;60:470-512.

82. Astrup A, Carraro R, Finer N, et al. Safety, tolerability and sustained weight loss over 2 years with the once-daily human GLP-1 analog, liraglutide. Int J Obes (Lond). 2012;36:843-854.

83. Rosenstock J, Klaff LJ, Schwartz S, et al. Effects of exenatide and lifestyle modification on body weight and glucose tolerance in obese subjects with and without pre-diabetes. Diabetes Care. 2010;33(6): 1173-1175.

84. Dushay J, Gao C, Gopalakrishnan GS, et al. Short-term exenatide treatment leads to significant weight loss in a subset of obese women without diabetes. Diabetes Care. 2012;35:4-11.

85. Gilor C, Graves TK, Gilor S, Ridge TK, Rick M. The GLP-1 mimetic exenatide potentiates insulin secretion in healthy cats. Domest Anim Endocrinol. 2011;41:42-49.
86. Padrutt I, Zini E, Kaufmann K, Menard J, Lutz TA, Reusch CE Comparison of the glp-1 analogues exenatide (short-acting), exenatide (long-acting) and the DPP-4 inhibitor sitagliptin to increase insulin secretion in healthy cats [abstract]. J Vet Intern Med. 2012;26: $1520-1521$.

87. German AJ, Morgan LE. How often do veterinarians assess the bodyweight and body condition of dogs? Vet Rec. 2008;163:503-505.

88. Freeman L, Becvarova I, Cave N, et al. WSAVA nutritional assessment guidelines. Comp Contin Educ Vet. 2011;33:E1-E9.

89. Allan FJ, Pfeiffer DU, Jones BR, Esslemont DH, Wiseman MS A cross-sectional study of risk factors for obesity in cats in New Zealand. Prev Vet Med. 2000;46:183-196.

90. Cave NJ, Allan FJ, Schokkenbroek SL, Metekohy CA, Pfeiffer DU. A cross-sectional study to compare changes in the prevalence and risk factors for feline obesity between 1993 and 2007 in New Zealand. Prev Vet Med. 2012;107:121-133.

\section{Publish your work in this journal}

Veterinary Medicine: Research and Reports is an international, peer-reviewed, open access journal publishing original research, case reports, editorials, reviews and commentaries on all areas of veterinary medicine. The manuscript management system is completely online and includes a very quick and fair peer-review system.
Visit http://www.dovepress.com/testimonials.php to read real quotes from published authors. 